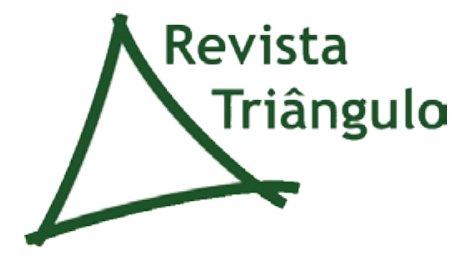

Uberaba, v. 5, n. 2 p. 85-99, jul./dez. 2012. ISSN: 2175-1609

OFICINAS DE FORMAÇÃO: OBSERVATÓRIOS DE ARTES E CONHECIMENTOS

TRAINING WORKSHOPS: OBSERVATORIES OF ARTS AND KNOWLEDGE

\author{
Helena Fontoura $^{1}$, Gianine Pierro ${ }^{2}$
}

\footnotetext{
${ }^{1}$ Professora Associada da Faculdade de Formação de Professores da Universidade Estadual do Rio de Janeiro (UERJ) . Docente no Programa de Pós-Graduação em Processos Formativos e Desigualdades Ssociais da UERJ. Email: helenafontoura@gmail.com

2 Professora Adjunta da Faculdade de Formação de Professores Universidade Estadual do Rio de Janeiro (UERJ). Email: gianine@oi.com.br
} 
Uberaba, v. 5, n. 2 p. 85-99, jul./dez. 2012. ISSN: 2175-1609

\title{
RESUMO
}

Este trabalho propõe questões que articulam os campos das artes e da formação docente quanto à produção e construção de conhecimentos, foco de nossa pesquisa nesta área, com o propósito de pensar contribuições para a reflexão sobre uma política de formação docente na visão democrática frente ao acesso aos bens de produção social e cultural, usando as bases do pensamento de Morin, Nóvoa e Maturana, entre outros autores. A presente comunicação se volta para o processo de construção de oficinas de imagens desenvolvidas em uma escola pública de um município do estado do Rio de Janeiro e conta com o envolvimento de professores e licenciandos que buscam cartografar o processo de apropriação e as falas do grupo quando provocado a expressar impressões e percepções de seus saberes e fazeres frente ao percurso de sua formação. Acreditamos contribuir para as reflexões sobre a formação de professores na parceria universidade-escola, instituições produtoras de saber e arte no sentido da socialização de conhecimento e de cultura.

Palavras-chave: Oficinas de imagem. Formação docente. Arte e conhecimento. Democratização de saberes e da cultura. Relação universidade - escola básica.

\begin{abstract}
This paper proposes questions that articulate the fields of Arts and teacher education, regarding the production and construction of knowledge, focus of our research in this area with respect to think contributions on reflections about a teacher training policy in democratic vision regarding access to social and cultural production, using the theoretical thoughts of Morin, Nóvoa and Maturana, among others. This communication turns to the process of building image related workshops developed in a public school of municipality in the State of Rio de Janeiro, with the involvement of teachers and teachers to be, where we seek to map the process of appropriation and the speeches of the group when provoked to express impressions and perceptions of their knowledge and practices outside the course of their training. In doing so, we believe to contribute with reflections on teacher training in university-school partnership, institutions that produce knowledge and art in the sense of the socialization of knowledge and culture.
\end{abstract}

Keywords: Image workshops. Teacher education. Art and knowledge. Democratization of knowledge and culture. University-school relationship. 


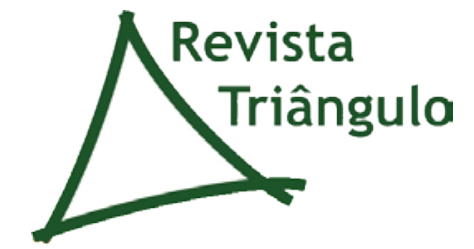

\section{OFICINAS DE FORMAÇÃO: OBSERVATÓRIOS DE ARTES E CONHECIMENTOS}

Sabedoria pode ser que seja ser mais estudado em gente do que em livros.

Manoel de Barros ${ }^{\mathrm{i}}$

Escrever é sempre colocar em palavras o que pensamos e sentimos e, quando colocamos no papel, nossos pensamentos e sentimentos já não nos pertencem, passam a ser de quem nos lê e de quem nos interpreta. Por isso, precisamos ser precisos sobre o que falamos, pelo menos para garantir um início de diálogo. Assim, falamos neste trabalho de uma inserção de quem faz e pensa formação de professores qualificada e contextualizada. Trabalhamos o tema a partir dos referenciais de autores como Morin (2000, 2001), Nóvoa (1992,1994), Maturana (2001, 2002), em busca da arte e dos saberes de ser e de se fazer professor.

Entendemos que Educação não é um processo que ocorre apenas nas escolas, aprendizagem é um conceito mais amplo, podendo ser entendido como a forma como vemos e vivemos a vida, nosso jeito de olhar o mundo, de buscar novos mundos, de experimentar, enriquecer pensamentos e sentimentos, de buscar prazer nas coisas e na convivência com pessoas com quem aprendemos e (com)vivemos.

O significado do desenvolvimento pessoal e profissional mesclado à dimensão coletiva do ensinar e do aprender não comporta a visão de processo cumulativo de conhecimentos dispostos de forma compartimentada: cursos, teorias, livros e técnicas. A concepção e análise dos contextos e relações sociais que produzem um conjunto de valores, saberes e atitudes imprimem à educação sua dimensão de experiência humana.

Por essa razão, consideramos fundamental trazer para o palco dessa formação a arte como um paradigma de autoria e autoridade em que professores ressignifiquem suas práticas e teorias. Para Geertz (1997), “estudar a arte é explorar uma sensibilidade; e que esta sensibilidade é essencialmente uma formação coletiva” (p. 149).

Na história da vida e da cultura humanas a arte ocupa um espaço próprio. A configuração do espaço escolar em sintonia com o tempo criativo e com a escuta sensível - estimulada pela arte - pode transpor a dimensão temporal e refazer o desenho de formação do aluno e do professor. Nesse outro esboço afloram questões e procedimentos viscerais à construção da 
identidade, ao senso de pertencimento, colocando professor e aluno frente a si mesmos, ao outro e ao mundo.

No pensamento de Maturana (2001), a arte existe no domínio psíquico da cultura, e por isso o autor afirma que vivemos experiências estéticas em todos os domínios relacionais com os quais lidamos. Compreendendo a arte no viés desse enquadramento teórico, afirma:

É devido ao fundamento biológico da experiência estética, bem como ao fato de que tudo que vivemos como seres humanos pertence à nossa experiência relacional, que a arte se entrelaça em nossa existência social e nosso presente tecnológico em qualquer época. (MATURANA, 2001, p.195)

Algumas questões surgem nesse percurso articulador de educação e arte: qual a função da educação associada à arte e como pode a arte ajudar nos processos de formar e (trans)formar? Entendemos a arte como busca de vitalidade e não de verdade (NIETZSCHE, 1998). Nessa perspectiva, trabalhamos a arte como ativação do sujeito, busca de vitalidade indiferenciada em lugar de verdade única. O princípio de ativação do indivíduo pela arte favorece uma educação emancipatória (FREIRE, 1987) e, como tal, é uma alternativa viável ao que propomos e vemos como transformação pessoal e individual. A arte pode contribuir para o desenvolvimento em todas as dimensões - sejam elas cognitivas, sociais ou psicológicas - dos seres humanos, em todas as faixas etárias, em todos os estratos sociais, na medida em que a capacidade interpretativa e sensível está em cada pessoa, independentemente de suas características e pertencimentos. As obras de arte e as atividades artísticas trazem possibilidades infinitas.

Para Morin (2000, p. 45) as artes nos levam à dimensão estética da existência, já que em toda obra de arte, seja literatura ou cinema, poesia ou música, pintura ou escultura, "há um pensamento profundo sobre a condição humana”. Portanto, reconhecer a diversidade e as relações que vivemos no mundo de hoje nos faz dialogar com as diferenças. Mais do que dialogar, é necessário trabalhar e seguir trabalhando com elas, sem supor partir das diferenças para depois eliminá-las, mas reconhecendo que as desigualdades é que inferiorizam os diferentes.

O direito à diferença vem sendo fortemente afirmado por movimentos na sociedade contemporânea, que trazem impactos na educação, especialmente nas disputas relativas aos currículos escolares, portanto, na formação dos professores, colocando novas condições para a concepção e a consecução de políticas públicas voltadas ao social. Assim, o fator humano - quem 
ensina, quem aprende, quem faz a gestão do sistema e da escola e de que forma - destaca-se como polo de atenção dos grupos envolvidos no pensar e fazer educação.

Nos dizeres de Nóvoa (1991), uma proposta de formação continuada deve ser centrada na investigação e na reflexão. Aponta o autor para dois modelos de formação continuada, sendo um o chamado 'estruturante', organizado a partir de uma lógica de racionalidade técnica, e outro o 'construtivista', que propõe uma reflexão contextualizada. Compartilhamos da preferência do autor pelo segundo modelo, apontando ainda as cinco teses por ele elencadas para o que deva ser a formação continuada na perspectiva da construção: a) alimentar-se de perspectivas inovadoras; b) valorizar as atividades de autoformação participada e de formação mútua; c) alicerçar-se em uma reflexão na prática e sobre a prática; d) incentivar a participação de todos os professores em programas e em redes de colaboração; e) capitalizar as experiências inovadoras e as redes de cooperação existentes nos sistemas. (p. 21)

Assumindo o compromisso da formação docente, nós, formadores de professores, dialogamos permanentemente com o desafio de trazer à tona um ou outro aspecto desse processo que se dá pari passu com o pedagógico; construímos oficinas realizadas com professores de escolas públicas na cidade de São Gonçalo, no estado do Rio de Janeiro, município que demanda grande necessidade de investimento em todas as áreas sociais, e especificamente em educação. O espaço é partilhado com licenciandos que fazem Estágio Supervisionado na escola em que acontece a oficina. Essa articulação universidade - escola básica, professores e licenciandos tem sido um grande diferencial nas propostas formativas empreendidas pelo grupo de pesquisa.

\section{OFICINAS E OFÍCIOS: DA ARTE E DOS SABERES DA PROFISSÃO}

Nos grupos sociais em que circulamos, é comum nos perguntarmos o que fazemos, que ofício exercemos, sendo essa uma forma de nos revelarmos inseridos na complexa teia social. Ninguém é capaz de exercer todas as funções necessárias para que a sociedade funcione, então, nossa identidade é ao mesmo tempo alteridade, já que o que nos constitui é diferente do que 
constitui os outros; cada profissão tem seu papel social, que nos faz ser reconhecidos e estabelecer relações. Em nosso caso, do ofício de professor, ensinamos a outros o que estes não sabem, ou ainda não sabem que sabem, ou que apenas não sistematizaram esse saber.

Para Souza Neto (2005), o exercício de qualquer ofício pressupõe que quem o exerce domine os processos que lhe são inerentes e seja capaz de executá-lo de maneira a observar como cada momento, cada detalhe, cada gesto resulta de uma unidade em que os fragmentos só justificam sua existência por fazerem parte do todo. Para o autor, os ofícios, como decorrentes de um dado ritual, requerem oficinas, lugares onde se devem encontrar os artefatos para o trabalho a matéria-prima que se manipulará, as ferramentas de que se disporá para a tarefa, os espaços em que o corpo se flexionará assumindo várias formas para o uso da força e da delicadeza em diferentes medidas.

Sendo a oficina o espaço em que os rituais de um dado ofício se realizam, poderíamos então dizer que certos fazeres e saberes estão sempre situados quando se conjugam enquanto aquela ação consciente que produz objetos materiais e imaterialidades simbólicas. Ao dizer situados, pressupõe-se a perspectiva de um lugar de onde. A partir desse processo, que inclui rituais constitutivos de coisas e ideias, instituem-se procedimentos, códigos, relações que identificam naqueles que fazem a oficina funcionar, os sujeitos que são (re)feitos pelo ofício que executam. Vale lembrar, portanto, que a ‘oficina’ é o lugar em que ocorrem transformações.

Em outras palavras, a realização de um ofício no interior de uma dada oficina cria, dentre outras coisas, uma identidade entre os indivíduos e os objetos que estes manipulam, as ferramentas que manuseiam, os processos com os quais interagem.

Como foco da pesquisa é a área de formação docente, voltamos nossa reflexão para diferentes aspectos em que a expressões e os processo de criação se presentificam através de diferentes expressões artísticas, seja nas produções textuais que esse grupo de pesquisa vem socializando, escritas por professores ou estudantes integrantes do grupo, seja nas pesquisas de campo que acontecem em escolas do município de São Gonçalo.

Reconhecemos o transitar pelas linguagens artísticas como uma tônica frequente com a qual convivemos em nosso processo de formação docente e também nas práticas formativas que desenvolvemos. Não se trata de inovação, mas de apropriação, de escolha política, de enveredar pelo caminho .... Como nos diz Guimarães Rosa, em Grande Sertão: Veredas, “o real não está na 
saída nem na chegada; ele se dispõe para gente é no meio da travessia”. Assim, nossa produção de conhecimento é criação, é modo de existir, de produzir a si e ao mundo, atravessando os muitos temas que nos “atravessam”.

Ao exercer nosso lugar de pesquisadoras, buscamos fazer o que Kastrup (2007) chama de cartografia, que é uma proposta de pesquisa que acompanha a processualidade do objeto que estuda e não busca apenas sua representação estática. A processualidade se abre ao arranjo de forças e aos seus embates. O sentido é que é o caminho, o percurso da investigação vai estabelecendo suas metas e seus encontros. Passos, Kastrup e Escóssia (2009) falam de pistas que objetivam sensibilizar quem pesquisa para o que o campo traz, servindo como calibragem para reinventar os caminhos da pesquisa, posição que nos conforta e com a qual concordamos.

Kastrup e Barros (in PASSOS et al, 2009) falam também das oficinas artísticas como espaços de produção de subjetividade e aprendizagem, possibilitando a ação de dispositivos concretos. Para os autores, dispositivos aliam-se aos processos de criação no trabalho do pesquisador, implicando acompanhamento, desdobramento, e não apenas fazer funcionar. Um dispositivo faz movimento, traz tensão ao campo, é composto por conexões, promove outras conexões, desbloqueia códigos, e vai assim adquirindo seu sentido único.

Das muitas oficinas acontecidas, um trabalho que está sempre em processo, dos territórios de criação e autocriação, destacamos na presente comunicação uma oficina em que imagens são nosso veículo de (trans)forma-ação, nossos dispositivos, uma vez que apostamos na ideia de que a imagem revela, provoca rupturas entre processos e noção temporal, reconfigura percepção e interpretação, forçando-nos a conhecer algo. Para além do registro e da documentação visual do ‘instantâneo da experiência’, destacamos a importância de dedicar maior atenção aos significados culturais engendrados pelas imagens, bem como às formas pelas quais a produção e a leitura dessas imagens são mediadas.

O trabalho com imagens em vários campos do conhecimento, além de oferecer a possibilidade de documentar e registrar a realidade social, pode auxiliar na interpretação das transformações ocorridas na vida social e cultural expressando a história social e política, os modos de vida, as práticas, o cotidiano.

Aqui surgem novas indagações: como pode ser desenvolvido o processo de alfabetização ii artística? Como o diálogo com as artes pode favorecer a criatividade e estimular o lado sensível 
do par educador/educando? Enfim, como a arte pode contribuir para a desautomatização da percepção do sujeito na contemporaneidade?

É a possibilidade de relacionar teoria e prática que reside na e faz da educação um ato criador, assim como a arte, na qual o artista transforma materiais amorfos em obras únicas e singulares. Essa criação é que muda o estabelecido, que possibilita a transformação de cada sujeito e do meio social que o circunda.

A escolha, para a oficina-objeto deste relato, das ilustrações críticas produzidas por Pawel Kuczynski $^{\text {iii }}$ se deu já que esse artista explora em suas imagens temas importantes da atualidade para o mundo, articulando forma, cor e significado a conceitos e visão de mundo - bases da contemporaneidade, espaço de possibilidades para a formulação e reflexão no campo da educação. Muitas de suas ilustrações se prestam a diferentes perspectivas de entendimento e interpretação, bem de acordo com o nosso propósito de oferecer pluralidade de possibilidades de entendimento do que é visto e percebido.

\section{DA ARTE: SABERES E OFÍCIOS DA PROFISSÃO}

A nossa prática docente tem reforçado o pensamento de que a arte - stricto e lato sensu desenvolve os mais variados níveis cognitivos e comportamentais: estimula o trabalho coletivo, o entrosamento, o compartilhamento, a disciplina, o esforço, o ensaio, a leitura, a coordenação motora, a organização mental, o mecanismo associativo, as habilidades corporais, a integração mente/corpo, tudo aliado ao prazer da descoberta, da estimulação sensorial e mais, do reconhecimento social junto à valorização do indivíduo. Ressalvamos aqui um dado importante, consoante à nossa prática docente: lidar com arte não significa ser um expert em tal ou qual modalidade artística. A eficácia do trabalho com a arte em suas diversas modalidades vem, muitas vezes, do contato com materiais diversos, sentimentos, técnicas, com as próprias dificuldades e possibilidades de comunicação e expressão, com o prazer das vivências compartilhadas.

Ao mesmo tempo, a arte materializa o imaginário de uma época, de uma sociedade, das diversas culturas que dialogam na contemporaneidade. O imaginário é algo muito semelhante ao 
material simbólico e constitui parte do nosso acervo cultural. Nessa perspectiva, o imaginário é desencadeado por um mecanismo associativo que faz com que determinados cheiros, sons, movimentos ou cenas desencadeiem memórias, sensações e até algum conceito subjetivo sem, necessariamente, relacioná-lo a outros conceitos ideológicos que emergem conjuntamente com essa ideia.

Por esse viés, é importante expor alunos e professores ao contato com a arte. Como manifestação estética, como representação simbólica dos anseios humanos, a obra artística é um conjunto de procedimentos, modos de composição que dizem respeito ao contexto históricosocial em que foi produzida e aos efeitos que projeta na esfera da recepção. É curioso observar que, com todas as diferenças de foco e momento histórico, a arte está presente nas diversas concepções de educação, seja quando estas tangenciam a questão do belo da forma(ção), seja quando propagam a arte como (auto)construção do sujeito ou ainda quando se voltam ao entorno, à expressão do ser e à sua comunicação com o outro.

A abordagem das mensagens visuais é transdisciplinar na medida em que, conjugando uma série de disciplinas e saberes, redimensionam o papel da interpretação dos conceitos. A utilização das imagens na educação permite que se compreenda a produção de sentido nas sociedades humanas para além da fragmentação habitual que a visão clássica da prática científica imprime. Assim, imagens, fotografia, pinturas, esculturas, desenhos, charges, por exemplo, não seriam nunca explicados por eles mesmos, mas pela vida cultural de cada sociedade, significados num sistema cultural geral.

A imagem revela, provoca rupturas entre processos e noção temporal, reconfigura percepção e interpretação, forçando-nos a conhecer uma totalidade ou ideia. Para além do simples registro e da documentação visual do 'instantâneo da experiência', destaca a importância de dedicar maior atenção aos significados culturais engendrados pelas imagens, bem como às formas pelas quais a produção e a leitura dessas imagens são mediadas.

O reconhecimento da importância das culturas visuais no mundo contemporâneo e da necessidade de aprender a 'ler', produzir e interpretar criticamente as diferentes linguagens visuais não pode ser descartado por nós, professores. Entre o sujeito que olha e a imagem que elabora há muito mais do que os olhos podem ver. Esse é um processo dinâmico, contínuo, tenso e múltiplo, e cada vez mais presente na vida das pessoas. É justamente por considerar todos esses 
aspectos que as imagens nos impressionam, nos comovem, nos incomodam, enfim, imprimem em nosso espírito sentimentos diferentes.

A aproximação do universo das imagens nos permite afirmar que não é possível atribuir sentido unívoco a elas. O caráter das imagens é alterado de acordo com as suas especificidades, com o meio de comunicação onde são elaboradas, assim as imagens podem ser: fotográficas, fílmicas, televisivas, informáticas etc. Existe uma gramática da imagem que, sendo flexível, postula leis próprias e que necessitam de uma alfabetização, de uma linguagem específica, com valor próprio, que nos desafia a conhecer.

\section{FORMAÇÃO DOCENTE: CONHECIMENTOS E ARTES}

Seguindo o que nos diz Rubem Alves (1992), as palavras voam como um bando de pássaros selvagens que a tinta aprisiona ao papel para que a luz dos olhos possa libertá-las e fazer voar os sonhos, as ideias, as sensações. Criamos e cultivamos palavras que nos nutrem o corpo e a alma, tornando nossa vida uma busca pela compreensão de si e dos outros com quem convivemos em sociedade, criando identidades a partir de saberes e fazeres de nossos ofícios. Para viver nossas diversas faces - docentes ou não - construímos processos fundados no ensino e nas aprendizagens como práticas de observar e descrever, compreender e interpretar cenários para então intervir; propor ações e interagir com essa realidade em modos de criação e produção de saberes e conhecimento.

Um olhar inquieto que busca na memória a construção de novas relações com o mundo se apresenta como um irrecusável convite para quem é educador. A partir do contato, da exposição e da exploração das reproduções de obras selecionadas, por exemplo, podemos refletir sobre as dimensões e a articulação entre escola, conhecimento e cultura, contribuindo para a possibilidade de sentir e olhar o mundo, atitudes que consideramos importantes e básicas para a formação docente e a pesquisa nesse campo.

Nossas professoras e licenciandas em Pedagogia, reunidas em atividade semanal na escola, trabalharam sobre leituras de imagens a partir de diferentes provocações, descrevendo, atribuindo sentidos, intervindo, construindo textos e nomeando. O texto construído, objeto de nossa reflexão presente, “o que esta imagem ‘fala’ sobre o processo de formação”, trouxe a possibilidade de os 
participantes expressarem ideias e opiniões sobre processos de formação e autoformação, um dos objetivos de nossas investigações. Verificamos, ainda, a partir dos textos produzidos, diferentes níveis perceptivos sobre o processo de formação, desde o mais concreto até o mais abstrato, evidenciando diferentes níveis cognitivos que convivem em uma atividade com arte que não discrimina nem hierarquiza saberes, como acontece em geral em ambientes educativos formais.

O trabalho do artista selecionado para esse exercício leva a uma ressignificação das imagens que trazem vários sentidos; então fizemos um exercício de elaborar um texto coletivo que “dissesse” as falas em uma voz coletiva do pensar e "vi-ver" sobre formação, destacando temáticas presentes, como a curiosidade, o tempo, a rotina, a aceitação do outro, o fracasso, a persistência, a relação teoria-prática, a transmissão e produção de conhecimento, as mudanças e transformações, a dificuldade de sermos sujeitos do processo de ensinar, enfim, os dilemas do cotidiano e dos fazeres docentes. Da mesma forma que as imagens produzem sentido, produzimos sentido coletivamente no grupo reunido para pensar como fazemos educação.

Selecionamos, para ilustrar o presente texto, sobre o exercício com as imagens, em que podemos verificar o que estas imagens, não mais aprisionadas porque socializadas e debatidas em grupo de formação/pesquisa, 'falam' aos participantes sobre o processo de formação:

Como metáfora, o processo de ensino-aprendizagem assemelha-se ao plantio: fome de conhecimento, fome de saber, sede de passar o conhecimento para o outro. Devemos estar atentas à rotina, pensando e repensando para não perder o olhar 'curioso'. Às vezes existem lacunas que não são completamente preenchidas na teoria e só na prática conseguimos preencher, acreditando que de algum lugar aparecerão respostas/soluções para nossos contínuos e longos dilemas, buscando estratégias e pesquisando autores.

Ninguém fica impune às mudanças, sejam elas educativas ou não. A educação só começa, não tem fim, aprendemos todo o tempo, para sempre. É um processo dinâmico e interativo: aluno, professor, escola, família. Aceitar e respeitar o outro como ele é, aproveitando bem o nosso tempo, usufruindo das oportunidades e facilidades que a informática nos traz.

Em nosso entendimento, não nos propomos a ser especialistas nessa ou naquela área de conhecimento, nessa ou naquela forma de expressão artística. Se assim acontecer, ótimo, é um caminho. Se não, a atividade cumpriu a função artística no sentido amplo: o sujeito que se autoelabora e se torna, nos descaminhos da vida, a sua própria obra de arte.

É pensando nessas possibilidades que investimos em nossas pesquisas: (a) de relacionar 
teoria e prática, residindo e fazendo da educação um ato criador, assim como a arte; (b) de transformar materiais/ideias/aprendizagens (amorfos) em obras únicas e singulares. Essa criação é que muda o estabelecido, possibilita a transformação de cada sujeito e de sua compreensão e ação no meio social que o circunda, desenvolvendo o que consideramos aqui processo de alfabetização artística, nas bases da leitura de mundo entendida em Freire (1987).

De acordo com Silva (2012), o professor, a partir de sua prática pessoal, tem a possibilidade de exercer sua autonomia, criatividade e criticidade, visualizando novos horizontes frente às possibilidades de transformação. O autor defende a arte como base do processo de educação, já que assim professores se fortalecem para romper com hierarquias e métodos tradicionais, ressignificando o espaço escolar. Engajar-se em algum processo que envolva arte em qualquer dimensão pode abrir espaços internos nos professores e externos nos ambientes por onde circulam que fomentem revoluções na forma de exercermos nosso ofício, na maneira de nos percebemos enquanto pessoas e profissionais.

Assim, as pistas (PASSOS; KASTRUP; ESCÓSSIA, 2009) por nós produzidas no decorrer da oficina em tela nos levaram a reinventar usos de arte como mediadora nas ações formadoras de professores.

\section{LEITURAS E OBSERVATÓRIO}

Deixando de lado a rotina da repetição frequente nos ambientes de aprendizagem e iluminando nossos olhares com o brilho multicolorido provocado por ideias, sentimentos, sensações, percepções e indagações dos traços e das cores, (con)figurando novas relações com o mundo, trazemos para o cenário da formação e das aprendizagens docentes as inquietações e a imaginação vividas na escola, no conhecimento e na cultura.

Observamos as possibilidades que a arte proporciona circulando entre o plano cognitivo e o emocional, com forte projeção no social. Como propôs Maturana (2001), o artista como criador de uma realidade virtual destaca, nas práticas das oficinas com professores, uma realidade fundadora no curso da realidade humana. Reconhecemos nos saberes da profissão, acompanhando o pensamento desse autor, sermos cocriadores no fluir das realidades variáveis que vivemos. 


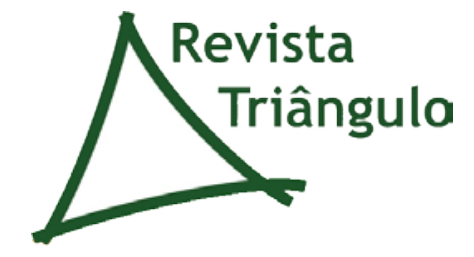

O professor, tanto aquele em processo inicial como o que está há tempos no magistério, se expressa; vê o resultado; acompanha o próprio crescimento e o dos demais naquela atividade; insere-se no grupo; aprende a compartilhar; fortalece a autoestima; trabalha a sensibilidade, a escuta, a fala, o movimento, práticas usuais e formativas para o ensino e a aprendizagem.

É nesse universo cultural que situamos nossa pesquisa. Vamos em busca de experiências que não se firmam pelo sentido da novidade ou do modismo, mas que se recuperaram na dimensão social e, nesse sentido, procuramos olhar a formação docente como um lugar onde, ao dar vitalidade ao presente, se constroem projetos de futuro coletivos. Através da atividade artística, temos contato com outras formas de potência que não necessariamente correspondem aos modelos massivamente divulgados pela mídia.

Pensamos, então, na importância de nossa profissão para a sociedade em que vivemos e para um futuro que podemos vislumbrar pleno de desafios de superação de modelos gastos. Nessa reflexão, acreditamos que temos também muito a aprender com os que sabem o que não sabemos, oportunidade ímpar que as artes proporcionam.

Educamo-nos para sermos sujeitos e atores, professores solidários e parceiros nas aprendizagens. Aos que optam por ser e/ou continuar professores por prazer, a vida na profissão é uma celebração diária, pessoal e coletiva, que transforma cada ato, mesmo nos dias mais difíceis, em uma reafirmação da escolha feita em certa altura da existência. E é essa mesma opção que nos leva aos congressos e encontros de formação continuada, às ruas para fazer valer nossos direitos, aos espaços educativos para exercer nosso ofício e, se possível, a refletir sobre o que fazemos e que ainda temos por fazer.

Como vimos, a arte, inspirada na noção nietzschiana, é vitalidade, estimula e energiza o sujeito com vistas à (auto)superação, o que sinaliza para uma educação emancipatória na acepção freireana. O indivíduo que alarga os seus limites, os seus horizontes, que se enfrenta, se confronta e se transforma reúne as condições para ser autônomo e exercer o que é possível exercer do livrearbítrio em contextos altamente consumistas como o que vivemos nos dias atuais.

Ampliando nosso pensar pelo pensamento de Maturana (2002), vivemos experiências estéticas em todos os domínios relacionais com os quais lidamos. Como seres humanos, a arte se entrelaça em nossa existência social e em nosso presente tecnológico em qualquer época. Podemos, através da atividade artística, ter contato com outras formas de potência que não 
necessariamente correspondem aos modelos massivamente divulgados pela mídia. Isso nos dá espaços interessantes de ressignificar a vida moderna, os impasses, dilemas e possibilidades, abrindo perspectivas críticas e formativas antes impedidas de circular pelo aparato capitalista que regula desde o financeiro ao emocional, transversalizando o pedagógico.

Temos então um papel formador dentro e fora de sala de aula, na escola, na rua, no pátio e em cada espaço que frequentamos. Um papel que é de formação para aquilo que se aprende no âmbito dos diversos saberes, sejam eles disciplinares ou não, e da educação para a política como espaço de disputa de projetos no mundo.

Tudo o que fazemos e vivemos tem a ver com a maneira como compreendemos nossas opções, tanto as pessoais, como desempenhar nosso ofício por prazer, como as coletivas, de nos ver como parte de uma totalidade social e política, reconhecendo nossa vontade e condição de operar transformações em diferentes níveis. Nesse sentido, a abordagem da arte é uma escolha sensível e eficaz e, como tal, produz ou sinaliza alternativas que nos incluem a todos num conjunto de procedimentos a que, então, gostaríamos de chamar: processos (trans)formativos.

\section{REFERÊNCIAS}

ALVES, R. O poeta. O guerreiro. O profeta. Petrópolis: Vozes, 1992

FREIRE, P. Pedagogia do Oprimido. 17. ed. Rio de Janeiro: Paz e Terra, 1987. Disponível em: < www.mda.gov.br/portal/saf/arquivos/view/ater/livros/pedagogia_do_oprimido.pdf>. Acesso em jul. de 2011.

GEERTZ, Clifford. A arte como um sistema cultural. In: .O saber local: novos ensaios em antropologia interpretativa. Petrópolis: Vozes, 1997.

KASTRUP,V. Atenção e autoprodução das práticas de si: deslocando a noção de autoestima. Anais do III Colóquio Franco Brasileiro de Filosofia da Educação. Foulcault 80 anos. 2006. ( digital)

MATURANA, H. Cognição, ciência e vida cotidiana. Belo Horizonte: Editora UFMG. 2001.

MATURANA, H. Emoções e Linguagens na educação e na política. Belo Horizonte: Editora UFMG. 5. ed., 2002. 
MORIN, Edgar. Ciência com Consciência. Rio de Janeiro: Bertrand do Brasil, 2001.

MORIN, Edgar. A Cabeça Bem-Feita: repensar a reforma, reformar o pensamento. Rio de Janeiro: Bertrand Brasil, 2000.

NIETZSCHE, Friedrich. Além do bem e do mal. Trad. Paulo. César de Souza. São Paulo: Companhia das Letras, 1998.

NÓVOA, A. Concepções e práticas de formação contínua de professores. In: Congresso Nacional de Formação Contínua de Professores: realidades e perspectivas, 1., 1991, Aveiro. Anais... Aveiro: Universidade de Aveiro, 1991. p. 15-38.

NÓVOA, A. Notas sobre formação (contínua) de professores. Conferência pronunciada na Faculdade de Educação da USP, em 17 de maio de 1994.

NÓVOA, A. (Org.) Vidas de Professores. Lisboa: Porto Editora, 1992a.

NÓVOA, A. A formação de professores e profissão docente. In: NÓVOA, A. Os professores e a sua formação. Lisboa: Dom Quixote, $1992 \mathrm{~b}$.

PASSOS, E.; KASTRUP, V..; ESCÓSSIA, L. (Orgs.) Pistas do método da cartografia. Porto Alegre: Sulinas, 2009.

SILVA, Valmir da. Contribuição da arte com seu significado histórico, social e cultural na formação do professor pedagogo.

Disponível em:

$<$ http://www.nupea.fafcs.ufu.br/pdf/8eraea/relatos_pesquisa/a_contribuica_da_arte.pdf $>$. Acesso em mar. de 2012.

SOUZA NETO, M.F. O ofício, a oficina e a profissão: reflexões sobre o lugar social do professor. Caderno Cedes, Campinas, vol. 25, n. 66, p. 249-259, maio/ago. 2005 Disponível em: <http://www.cedes.unicamp.br>. Acesso em fev. de 2011.

\footnotetext{
${ }^{\mathrm{i}}$ BARROS,M. Retrato do artista quando coisa. Rio de Janeiro: Record, 1997.

${ }^{\text {ii }}$ Entendemos aqui alfabetização na dimensão atribuída por Paulo Freire como leitura de mundo.

iii Artista polonês nascido em 1976 em Szczecin, formado com especialização gráfica na Academia de Belas Artes de Poznam. Imagens disponíveis em <http://haznos.org/2011/05/a-arte-satirica-e-genial-de-pawel-kuczynski/>. Acesso em set. de 2011.
} 